\title{
Green-light Supplementation for Enhanced Lettuce Growth under Red- and Blue-light-emitting Diodes
}

\author{
Hyeon-Hye Kim ${ }^{1}$ \\ NASA Biological Sciences Office, Mail Code YA-E4-B, Kennedy Space Center, \\ FL 32899 \\ Gregory D. Goins \\ North Carolina A\&T State University, Biology Department, Barnes Hall, 1601 \\ East Market Street, Greensboro, NC 27411
}

Raymond M. Wheeler and John C. Sager

NASA Biological Sciences Office, Mail Code YA-E4-B, Kennedy Space Center, FL 32899

Additional index words. dry-weight accumulation, photosynthesis, spectral quality, yield photon flux

\begin{abstract}
Plants will be an important component of future long-term space missions. Lighting systems for growing plants will need to be lightweight, reliable, and durable, and light-emitting diodes (LEDs) have these characteristics. Previous studies demonstrated that the combination of red and blue light was an effective light source for several crops. Yet the appearance of plants under red and blue lighting is purplish gray making visual assessment of any problems difficult. The addition of green light would make the plant leave appear green and normal similar to a natural setting under white light and may also offer a psychological benefit to the crew. Green supplemental lighting could also offer benefits, since green light can better penetrate the plant canopy and potentially increase plant growth by increasing photosynthesis from the leaves in the lower canopy. In this study, four light sources were tested: 1) red and blue LEDs (RB), 2) red and blue LEDs with green fluorescent lamps (RGB), 3) green fluorescent lamps (GF), and 4) cool-white fluorescent lamps (CWF), that provided $0 \%, 24 \%, 86 \%$, and $51 \%$ of the total $P P F$ in the green region of the spectrum, respectively. The addition of $24 \%$ green light $(500$ to $600 \mathrm{~nm})$ to red and blue LEDs (RGB treatment) enhanced plant growth. The RGB treatment plants produced more biomass than the plants grown under the cool-white fluorescent lamps (CWF treatment), a commonly tested light source used as a broad-spectrum control.
\end{abstract}

Plants will be an integral part of any longterm future space mission. A major challenge to growing plants in space will be controlling and supplying a sufficient quantity and quality of light (Bugbee and Salisbury, 1988; Langhans and Dressen, 1988; Sager and Wheeler, 1992; Salisbury and Bugbee, 1988). Light-emitting diodes (LEDs) are a promising electric light source for space-based plant growth chambers and bioregenerative life support because of their small mass and volume, solid-state construction, superior safety, and longevity (Barta et al., 1992; Bula et al., 1991). Lightemitting diode lighting systems are currently under evaluation by NASA. The combination of red (600 to $700 \mathrm{~nm}$ ) and blue (400 to 500

\footnotetext{
Received for publication 18 Feb. 2004. Accepted for publication33 Mar. 2004. The authors would like to thank Johnny Burrows, Larry Koss, Holly Loesel, Jennifer Mathieu, Joey Norikane, and Charles Quincy for their support. Mention of a trade name or proprietary product does not constitute an endorsement, guarantee, or warranty by the National Aeronautics and Space Administration. Quantum Devices, Inc. (Barneveld, Wis.) holds a patent (No. 5,012,609) on light-emitting diodes as an illumination source for plant growth.

${ }^{1}$ National Research Council resident research associate.
}

$\mathrm{nm}$ ) light has proven to be an effective lighting source for producing spinach, radish, pepper, Swiss chard, wheat, and lettuce biomass in controlled environments (Brown et al., 1995; Goins, 2002; Goins et al., 1997, 2001; Goins and Yorio, 2000; Yorio et al., 1998, 2001).

Plant leaves readily absorb red and blue light, so absorptance is high and reflectance is relatively low in these ranges of the spectrum (Klein, 1992; Smith, 1993). Therefore, even healthy plants grown under red and blue LEDs alone appear purplish gray to humans. However, green light has a relatively higher reflectance than red and blue light (Klein, 1992; Smith, 1993). Hence, the addition of green light to red and blue LED arrays would enable plants to appear green to the crew. The familiar appearance of the plants would be aesthetically pleasing and would allow the crew to visually assess plant health status.

The addition of green light in combination with red and blue LEDs may promote increased plant growth, since green light can penetrate into the plant canopy better than red or blue light (Klein, 1992; Smith, 1993). Leaves in the lower canopy would be able to use the transmitted green light in photosynthesis.

Results from previous studies have been inconclusive as to the physiological benefits of green light. Dougher and Bugbee (2001b) reported that many previous controlled environment studies have been plagued with lighting problems. For example, Klein et al. (1965) reported that the supplemental green radiation (530 to $585 \mathrm{~nm}$ ) caused repressed growth of Targetes erecta and Sordaria fimicola, but the study reported light measurements in footcandles. Huh et al. (1997) reported that high green band output (500 to $600 \mathrm{~nm}$ ) increased plant height in Hibiscus syriacus. Song et al. (1997) reported that green light appeared to be the least effective in promoting plant growth and development in $H$. syriacus. These green light studies did not provide lighting sources with clean cut-offs. There was also incomplete information on the spectral outputs of the lighting and/or filter sources. Light-emitting diodes are well suited to test the use of supplemental green light on the growth of plants, since the lighting in the growing area can be well controlled. For the current study, small fluorescent lamps that emit green light were installed with an array of red and blue LEDs. This is due to the lack of available high output green LEDs that could provide the required photon flux.

For a space mission, highly optimized lighting systems are necessary to conserve power and maximize plant growth, so there is a need to investigate advanced lighting technologies. Among them, supplemental green light needs to be evaluated. Growing salad crops with LEDs would also fulfill NASA's near-term goal of supplementing the crew's diet with fresh salad-type (perishable) crops (Goins et al., 1998; Kliss and MacElroy, 1990; Salisbury and Clark, 1996). We are not aware of reports on the response of lettuce to supplemental green light. The objective of this study was to investigate the effects of green light supplementation for growing lettuce under red and blue LEDs.

\section{Materials and Methods}

Cultural conditions. Lettuce seeds (Lactuca sativa 'Waldmann's Green') were planted in plastic pots $(7 \mathrm{~cm}$ tall, $164-\mathrm{mL}$ capacity, two seeds per pot) containing horticultural vermiculite and Canadian sphagnum peatmoss (Terra-Lite Agricultural Mix; The Scotts Co., Marysville, Ohio). Within the growth chamber (PGW-36; Conviron, Pembina, N.D.; 7.8- $\mathrm{m}^{3}$ interior plant growth volume), 16 pots were arranged inside of a $0.3-\mathrm{m}^{2}$ tray under each light treatment. The lighting treatments were systematically rotated for each replication to minimize edge or position effects within the growth chamber. To further minimize any edge or position effects within each treatment the pots were rearranged every other day. At $7 \mathrm{~d}$ after planting (DAP), the lettuce seedlings were thinned to a density of one plant per pot. The air temperature, relative humidity, and $\mathrm{CO}_{2}$ levels for all treatments were maintained at $21 \pm 0.3{ }^{\circ} \mathrm{C}, 70 \% \pm 4.1 \%$, and $1200 \pm 48.9$ $\mu \mathrm{mol} \cdot \mathrm{mol}^{-1}(0.12 \mathrm{kPa})$, respectively. Fresh half-strength Hoagland's nutrient solution (Hoagland and Arnon, 1950; Mackowiak et al., 1989) was added as needed to the bottom of each tray to supply nutrients and replenish 
Table 1. Spectral data for red and blue light-emitting diodes (LEDs) (RB), red and blue LEDs with green fluorescent lamps (RGB), green fluorescent lamps (GF), and cool-white fluorescent lamps (CWF). Spectral scans were recorded at the top of the plant canopy with a spectroradiometer.

\begin{tabular}{|c|c|c|c|c|}
\hline \multirow[b]{2}{*}{ Parameter } & \multicolumn{4}{|c|}{ Treatment } \\
\hline & $\overline{\mathrm{RB}}$ & RGB & GF & CWF \\
\hline \multicolumn{5}{|l|}{$\overline{\text { Photon flux }\left(\mu \mathrm{mol} \cdot \mathrm{m}^{-2} \cdot \mathrm{s}^{-1}\right)}$} \\
\hline PPF (400-700 nm) & 150 & 150 & 150 & 150 \\
\hline Blue (400-500 nm) & 24 & 23 & 15 & 29 \\
\hline Green (500-600 nm) & 0 & 36 & 129 & 76 \\
\hline $\operatorname{Red}(600-700 \mathrm{~nm})$ & 126 & 92 & 6 & 45 \\
\hline Far-red (700-800 nm) & 2 & 2 & 2 & 7 \\
\hline Yield photon flux ${ }^{z}$ & 130 & 127 & 122 & 134 \\
\hline \multicolumn{5}{|l|}{ Fraction $(\%)$} \\
\hline PPF & 100 & 100 & 100 & 100 \\
\hline Blue & 16 & 15 & 10 & 19 \\
\hline Green & 0 & 24 & 86 & 51 \\
\hline Red & 84 & 61 & 4 & 30 \\
\hline \multicolumn{5}{|l|}{ Ratios } \\
\hline Red : far-red & 63 & 46 & 3 & 6 \\
\hline Blue : red & 0.2 & 0.3 & 2.5 & 0.6 \\
\hline Blue : far-red & 12 & 12 & 8 & 4 \\
\hline Calculated $\mathrm{P}_{\mathrm{fr}} / \mathrm{P}_{\text {total }}^{\mathrm{z}}$ & 0.86 & 0.86 & 0.80 & 0.83 \\
\hline \multicolumn{5}{|l|}{ Irradiance $\left(\mathrm{W} \cdot \mathrm{m}^{-2}\right){ }^{\text {trotal }}$} \\
\hline $280-2,800 \mathrm{~nm}$ & 28 & 33 & 39 & 41 \\
\hline $2,800-50,000 \mathrm{~nm}$ & 2 & 13 & 134 & 16 \\
\hline
\end{tabular}

${ }^{\mathrm{z}}$ Calculated according to Sager et al. (1988).

evapotranspiration water losses.

Light treatments. The four light sources were 1) red and blue LEDs (RB), 2) red and blue LEDs with green fluorescent lamps (RGB), 3) green fluorescent lamps (GF), and 4) cool-white fluorescent lamps (CWF). Figure 1 shows the spectral distribution scans taken (at approximately equal total photosynthetic photon flux, $P P F, 400$ to $700 \mathrm{~nm}$ ) from 300 to $1100 \mathrm{~nm}$ at $2 \mathrm{~nm}$ steps with a spectroradiometer (LI-1800; LI-COR, Lincoln, Neb.). Contributions of blue (400 to $500 \mathrm{~nm}$ ), green $(500$ to $600 \mathrm{~nm})$, red (600 to $700 \mathrm{~nm})$, far-red (700 to 800) and total PPF were determined from bandwidth integration. From the spectroradiometric data for each light treatment the yield photon flux (YPF; Sager et al., 1988), the quantum ratios of red, far-red, blue, and the calculated amount of phytochrome in $\mathrm{P}_{\mathrm{fr}}$ form relative to total phytochrome at photoequilibrium ( $\mathrm{P}_{\mathrm{fr}} / \mathrm{P}_{\text {ital }}$; Sager et al., 1988) were determined. Short-wave (280 to $2,800 \mathrm{~nm}$ ) and thermal long-wave (2,800 to $50,000 \mathrm{~nm})$ radiation were measured with Eppley PSP and PIR radiometers (Eppley Laboratories, Newport, R.I.) (Table 1).

For RB treatments, plants were grown under nine LED arrays (Snap-Lite; Quantum Devices, Inc., Barneveld, Wis.) equipped with red gallium-aluminium-arsenide (GaAlAs) and blue gallium-nitride (GaN) LEDs. Each array contained 150 red and 75 blue individual diodes. For RGB treatments, four green fluorescent lamps (F15T8/G; Interlectric Corp., Warren, Pa.) were mounted around another set of nine red and blue LED arrays (Snap-Lite) and supplied $24 \%$ green light of the total $P P F$. For GF treatments, plants were grown under six green fluorescent lamps (F15T8/G; Interlectric Corp., Warren, Pa.) that provided $86 \%$ green light of the total PPF. For CWF treatments, plants were grown under 12 cool-white fluorescent lamps (F15T12-CW; General Electric Co., Cleveland, Ohio) with a 3.5-mm-thick Plexiglas heat barrier that provided $51 \%$ of the total $P P F$ in the green region of the spectrum. A vestibule made of black, opaque plastic precluded light noise from entering growth area that contained LED arrays and fluorescent lamps.

Lighting for all treatments was $18-\mathrm{h}$ photoperiod (18-h light/6-h dark) with approximately equal $P P F$ at $150 \mu \mathrm{mol} \cdot \mathrm{m}^{-2} \cdot \mathrm{s}^{-1}$ $\left(9.7 \mathrm{~mol} \cdot \mathrm{m}^{-2} \cdot \mathrm{d}^{-1}\right)$. Photosynthetic photon flux levels were measured at the top of the plant canopy with a quantum sensor (LI-190SA; LI-COR) calibrated with a spectroradiometer (LI-1800). As the plant canopies grew closer to the light banks, PPF levels were maintained by adjusting the height of the pots.

Plant measurements. Beginning at 7 DAP, four plants were harvested from each light treatment. Harvesting continued on a weekly interval with final harvest at 28 DAP prior to canopy closure to minimize spectral quality changes caused by canopy closure. Measurements included leaf area, specific leaf area (SLA), shoot fresh weight (shoot FW), and shoot dry weight (shoot DW). Due to the strong bond between the plant roots and the potting media, measurements did not include root fresh and dry weights. Only the edible biomass was measured. Plant tissue samples were dried in a drying oven for $48 \mathrm{~h}$ at $70{ }^{\circ} \mathrm{C}$ before weighing. Standard growth analysis was used to calculate leaf area index (LAI, $\mathrm{m}^{2} \cdot \mathrm{m}^{-2}$ ) and crop growth rate (CGR) for the 7-d interval based on average values. Chlorophyll (Chl) measurements were made using several representative samples from leaves and analyzed by the method of Moran (1982). Canopy leaf temperature data were logged under each lighting source with infrared transducers (model IRTS-P; Apogee Instruments Logan, Utah).

At 28 DAP and $2 \mathrm{~h}$ after onset of the photoperiod, photosynthetic rates (Pn) were measured from four of the youngest fully expanded leaves per treatment using a portable photosynthesis system (LI-6400; LI-COR). The red (630 $\pm 10 \mathrm{~nm}$ peak wavelength) and blue $(470 \pm 10$ nm peak wavelength) LED light source built into the leaf cuvette was calibrated against an internal photodiode. The measurements were alternated among the treatments. During all measurements, $P P F$, leaf temperature, relative humidity, and $\mathrm{CO}_{2}$ levels within the cuvette were held at $150 \mu \mathrm{mol} \cdot \mathrm{m}^{-2} \cdot \mathrm{s}^{-1}, 21{ }^{\circ} \mathrm{C}, 65 \%$, and $1200 \mu \mathrm{mol} \cdot \mathrm{mol}^{-1}$, respectively.

Measurements of leaf reflectance and transmittance were made using an external integrating sphere (1800-12S; LI-COR) internally coated with a highly reflective, diffusive material, barium sulfate and coupled to a spectroradiometer (LI-1800; LI-COR) with a fiber optic cable. Collimated light was provided by a 10-W glass-halogen lamp (Sylvania, Danvers, Mass.) stabilized by a regulated power supply (1800-12B; LI-COR). Measurements of reflectance and transmittance were made from leaves by scanning from 400 to $700 \mathrm{~nm}$ at $29 \mathrm{DAP}$. Absorptance was calculated as absorptance = 1-(reflectance + transmittance).

Statistical analysis. The experiment was repeated three times with means calculated from 16 plants per repetition. Using 5\% as the level of significance, statistical analysis was subjected to analysis of variance followed by Duncan's multiple range tests (SPSS Inc., Chicago, Ill.).

\section{Results and Discussion}

The LEDs used in this study had narrow spectral outputs $(25 \mathrm{~nm}$ band width at half peak height) in each red and blue region of waveband. The narrowly distributed spectra of the LEDs were in contrast to the broad spectrum of green and cool-white fluorescent lamps (Fig. 1). The lower relative weighting of the blue (400 to $500 \mathrm{~nm}$ ) and red (600 to $700 \mathrm{~nm}$ ), and the higher weighting of the green (500 to $600 \mathrm{~nm}$ ) reduced the YPF for the green fluorescent lamps. The red to far-red ratio of the GF and CWF were 3 and 6, respectively, whereas that of RB and RGB were 63 and 46, respectively. The calculated $\mathrm{P}_{\mathrm{fr}} / \mathrm{P}_{\text {total }}$ values for all the treatments were $\geq 0.80$. More long-wave radiation was measured from the GF lamps than from the other lighting treatments (Table 1), but this did not significantly impact the average canopy leaf temperatures among the different treatments (Table 2).

Table 2 shows the results of the physiological measurements from all treatments. The plants with the greatest leaf area were grown under RGB, followed by RB and CWF, and then GF. The specific leaf area of the GF treatment plants was the highest among the treatments, followed by RB and CWF, and then RGB. The RGB plants also had the greatest shoot fresh and dry weights with the RB and $\mathrm{CWF}$, and then GF treatments following in descending order. The photosynthetic rates were lower in plants grown under GF and there was no significant difference in chlorophyll content among treatments (Table 2). Leaf area index and CGR were decreasing in the order of plants grown under RGB, CWF, RB, and GF (Fig. 2).

Yield photon flux (YPF) has been used as a tool for explaining biomass accumulation 


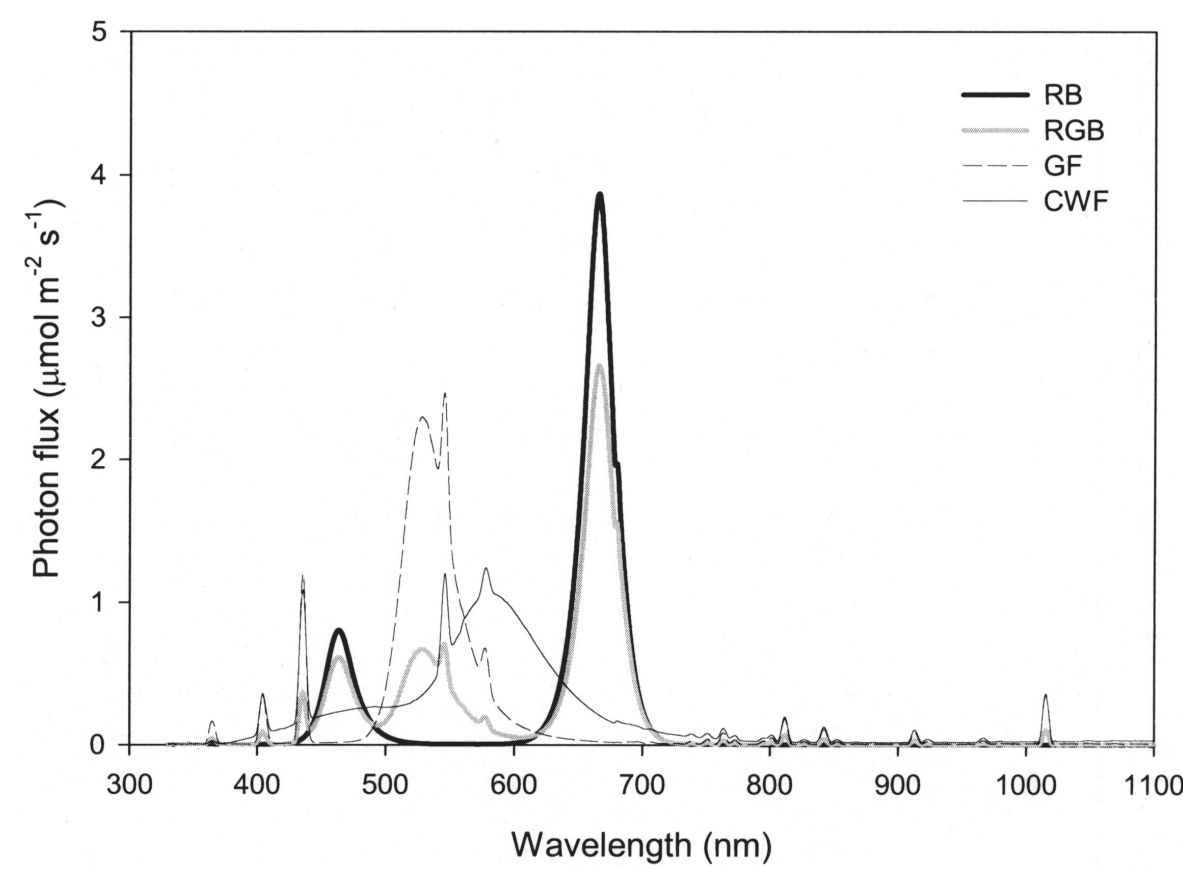

Fig. 1. Spectral distribution of light from red and blue LEDs (RB), red and blue LEDs with green fluorescent lamps (RGB), green fluorescent lamps (GF), and cool-white fluorescent lamps (CWF). Spectral scans were recorded at the top of the plant canopy with a spectroradiometer.

Table 2. Influence of light quality on leaf area, specific leaf area (SLA), shoot fresh weight (shoot FW) shoot dry weight (shoot DW), single leaf net photosynthesis (Pn), total chlorophyll (Chl) content, and canopy leaf temperature at $28 \mathrm{~d}$ after planting.

\begin{tabular}{lcccc}
\hline & \multicolumn{4}{c}{ Treatment $^{z}$} \\
\cline { 2 - 5 } Parameter & RB & RGB & GF & CWF \\
\hline Leaf area $\left(\mathrm{cm}^{2}\right)$ & $524.8 \mathrm{~b}^{y}$ & $689.9 \mathrm{a}$ & $419.2 \mathrm{c}$ & $595.3 \mathrm{~b}$ \\
$\mathrm{SLA}\left(\mathrm{m}^{2} \cdot \mathrm{kg}^{-1}\right)$ & $34.1 \mathrm{~b}$ & $30.1 \mathrm{c}$ & $49.4 \mathrm{a}$ & $33.9 \mathrm{~b}$ \\
Shoot $\mathrm{FW}(\mathrm{g})$ & $24.6 \mathrm{~b}$ & $35.7 \mathrm{a}$ & $15.3 \mathrm{c}$ & $26.9 \mathrm{~b}$ \\
Shoot DW $(\mathrm{g})$ & $1.54 \mathrm{~b}$ & $2.26 \mathrm{a}$ & $0.83 \mathrm{c}$ & $1.76 \mathrm{~b}$ \\
Pn $\left(\mu \mathrm{mol} \mathrm{CO}_{2} / \mathrm{m}^{2} / \mathrm{s}\right)$ & $9.3 \mathrm{a}$ & $8.6 \mathrm{a}$ & $7.4 \mathrm{~b}$ & $8.8 \mathrm{a}$ \\
Chl $\left(\mathrm{g} \cdot \mathrm{m}^{-2}\right)$ & $0.21 \mathrm{a}$ & $0.21 \mathrm{a}$ & $0.18 \mathrm{a}$ & $0.20 \mathrm{a}$ \\
Canopy leaf temperature $\left({ }^{\circ} \mathrm{C}\right)$ & $20.5 \mathrm{a}$ & $20.4 \mathrm{a}$ & $20.7 \mathrm{a}$ & $20.3 \mathrm{a}$ \\
\hline
\end{tabular}

${ }^{2}$ See Fig. 1 and Table 1 for spectral characteristics.

${ }^{y}$ Mean comparison within a row by Duncan's multiple range test, $P=0.05$. Means with same letter are not significantly different.

because it weighs photons according to their relative quantum efficiency for photosynthesis (McCree, 1972a; Sager et al., 1988). The use of YPF to accurately describe dry-weight accumulation has been demonstrated in wheat (Triticum aestivum) and soybean (Glycine max), but not in lettuce (Dougher and Bugbee, 1999, 2001a; Yorio et al., 2001). In this research, the average $P P F$ was $150 \mathrm{umol} \cdot \mathrm{m}^{-2} \cdot \mathrm{s}^{-1}$ and the YPF for RB, RGB, GF, and CWF were 130, 127, 122, and $134 \mu \mathrm{mol} \cdot \mathrm{m}^{-2} \cdot \mathrm{s}^{-1}$, respectively (Table 1 ). The YPF was higher in the RB and CWF than RGB and GF, yet the DW accumulation was higher under RGB than under RB and CWF (Table 2). This suggests that using YPF to compare plant growth between spectrally biased and broad-spectrum sources may not be valid.

Plants grown under RB and CWF had similar DW accumulation. This indicated that normal growth for lettuce could be achieved with only red and blue photons. Yorio et al. (2001) reported similar results for lettuce ('Waldmann's Green') when plants were grown with red LEDs with blue fluorescent lamps. Hoenecke et al. (1992) suggested that light treatments comprising five blue light fractions: $0 \%, 2 \%$, and $6 \%$ from high-pressure sodium (HPS) lamps and 6\%, 12\%, and $26 \%$ from metal halide (MH) lamps. Lettuce chlorophyll concentration, dry weight, leaf area and specific leaf area under the HPS and MH $6 \%$ blue were significantly different, which suggested that yellow light from 580 to 600 $\mathrm{nm}$ suppressed plant growth. In the present study, the yellow light (580 to $600 \mathrm{~nm}$ ) fractions for RB, RGB, GF, and CWF were $0 \%$, $1 \%, 4 \%$, and $17 \%$ of total $P P F$, respectively. The data from this study do not suggest yellow light suppression of lettuce growth, since the DW of RB (0\% yellow light) and CWF (17\% yellow light) plants were similar (Table 2). Apparently the response of different plant species or cultivars under various light environments is too complicated to interpret using one quantitative light quality parameter (Kim et al., 2002; Rajapakse et al., 1992).

The red and blue LEDs with 24\% green light treatment (RGB) gave the highest plant growth. The contribution made by green light transmission into the lower canopy could not be determined, since the lettuce plants were harvested prior to canopy closure to minimize the changes in spectral quality. In a dense canopy, the addition of green light may further increase plant growth, since green light can better penetrate into the plant canopy than red or blue light (Klein, 1992; Smith, 1993). Leaves in the lower canopy would be able to use the transmitted green light in photosynthesis and perhaps reduce levels of leaf senescence and/or shedding within the canopy (Preece and Read, 1993).

The addition of 5\% green light had negligible impact on plant growth and photosynthesis in our preliminary study (unpublished data). This was somewhat expected, since green light is only slightly less effective at photosynthesis than red or blue lights (McCree, 1972b) and drives carbon fixation deep within leaves (Sun et al., 1998). However, the addition of supplemental green light at higher input levels resulted in decreased plant growth. Among RGB, CWF, and GF plants, increasing the green light fraction to $24 \%, 51 \%$, and $86 \%$, respectively, decreased lettuce growth in terms of leaf area and dry weight. This suggested that light sources with a high fraction of green photons $(>50 \%)$, such as CWF and GF, are not only energetically wasteful compared to reduced green light sources, but they can also reduce plant growth.

Light, to be effective, must be intercepted and absorbed by photosynthetic tissue. The fraction of absorbed light for GF and CWF were relatively low, $63 \%$ and $73 \%$, respectively (Fig. 3 ). This was mainly due to the low absorption in green waveband (500 to $600 \mathrm{~nm}$ ) that was the main portion of the total $P P F$ in these treatments. However, the fraction of absorbed to incident light does not explain plant growth, since for $\mathrm{RB}$ the ratio was $89 \%$, compared to $82 \%$ for RGB (Fig. 3). The main difference between the $\mathrm{RB}$ and RGB treatments was RB had $0 \%$ green light while RGB had $24 \%$ green light.

Green light is often assumed to be unimportant in driving photosynthesis mainly 


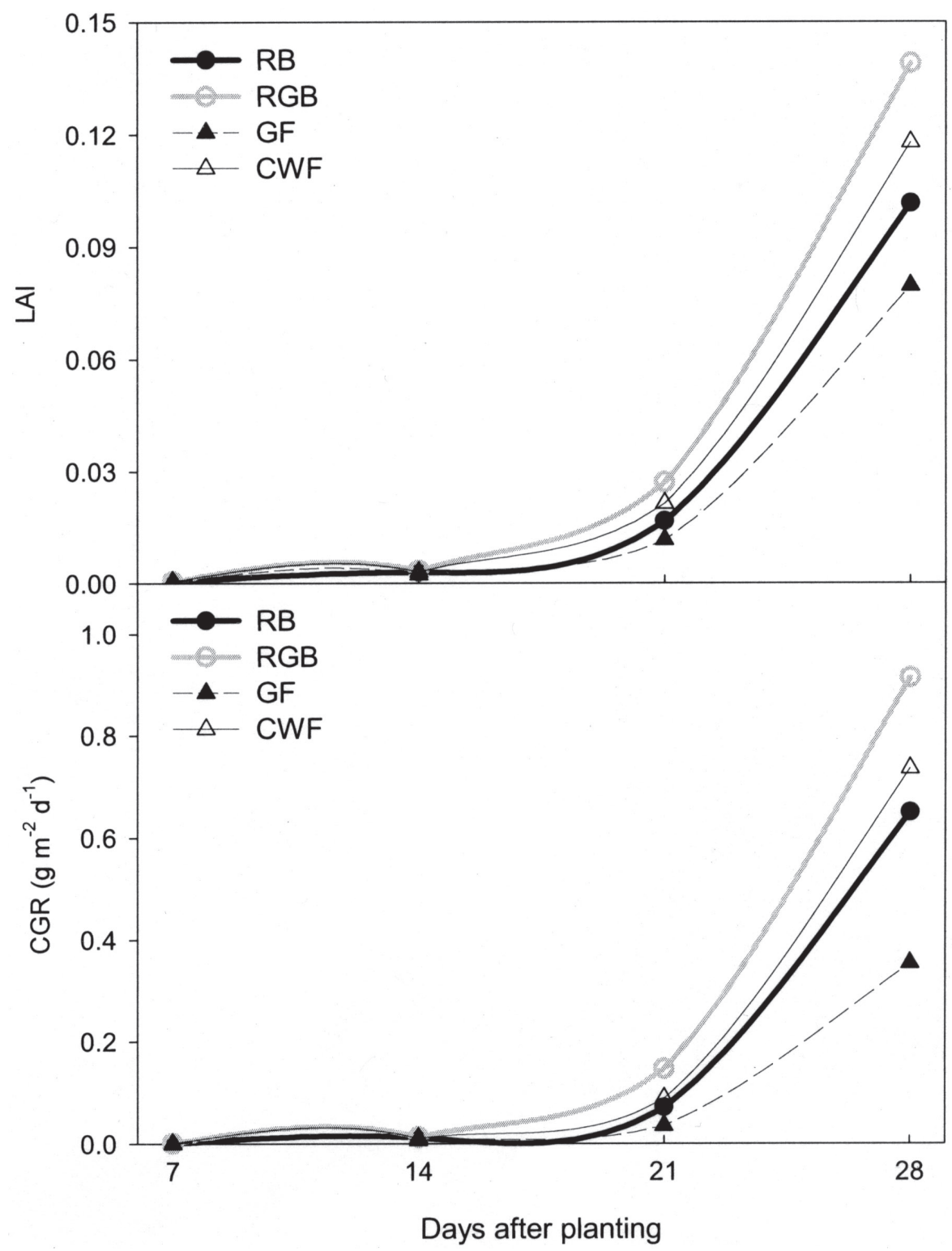

Fig. 2. Leaf area index (LAI) and crop growth rate (CGR) of lettuce grown under red and blue LEDs (RB), red and blue LEDs with green fluorescent lamps (RGB), green fluorescent lamps (GF), and cool-white fluorescent lamps (CWF). The data points are averages of 12 measurements. See Fig. 1 and Table 1 for spectral characteristics.

due to the low absorptivity coefficient in the absorption spectra of purified chlorophylls (Sun et al., 1998). Although the chances of green wavelengths being absorbed into the photosynthetic apparatus is small, the wavelengths not absorbed are repeatedly reflected from chloroplast to chloroplast in the complex network of photosynthetic cells. With each reflection, a small percentage of those wavelengths is absorbed, until finally half or more are absorbed by most leaves and are used in photosynthesis. In a spectrophotometer cuvette containing dissolved chlorophyll, the internal reflection does not occur, so the absorptance of green wavelengths is very low (Salisbury and Ross, 1992). The response spectra for photosynthesis shows that green light is in an effective spectral region to power photosynthesis in higher plants (McCree, 1972a). This may include absorption by ancillary pigments and transference of the energy to the reaction centers. In living leaves, light absorption by the carotenoids shifts from the blue portion of the spectrum into the green and some photosynthesis is conducted (Klein, 1992; Nobel, 1999; Salisbury and Ross, 1992; Taiz and Zeiger, 1991). Most of the carontenoids (both $\beta$-carotene and the xanthophylls) in the thylakoids efficiently transfer their excitation energy to the same reaction centers as do chlorophylls, also contributing to photosynthesis (Salisbury and Ross, 1992; Siefermann-Harms, 1985, 1987; Taiz and Zeiger, 1991).

Single-leaf photosynthetic rates were lower in plants grown under GF than RB, RGB, and CWF (Table 2). Lower Pn under GF may be associated with lower leaf mass per unit leaf area, i.e., higher specific leaf area (Table 2). The higher projected leaf area per unit leaf dry mass (equivalent to SLA) under GF is a good indicator of higher photosynthetic surface area per unit investment in leaf tissue and is often positively associated with shade-type physiology (Hanba et al., 2002; Lambers et al., 1998; Pearcy, 1998; Salisbury and Ross, 1992). This suggested that under the GF treatment with green-biased light more resources were allocated toward greater leaf area production, while carbon-assimilation capacity per unit leaf area was reduced compared to other treatments. The changes in leaf ultra structure among the spectral environments also could have significantly impacted the density of chloroplasts within the leaves or the proportion of incident light that is captured by the photosynthetic apparatus.

Although DW accumulation increased in plants grown under RGB, the leaf Pn were similar in plants grown under RB, RGB, and $\mathrm{CWF}$. Thus, leaf $\mathrm{CO}_{2}$ assimilation rates cannot fully explain the effect. A possible explanation for the discrepancy between Pn and DW accumulation could lie in the single point Pn measurements in this study. Diurnal Pn and dark respiration measurements of single leaves or whole canopies would be useful in determining the fate of carbon in plants grown under different light quality.

In the Pn measurement device, a red and blue LED light source was built into the leaf cuvette, which had a similar light quality only to the RB treatment. Plant photosynthetic performance may be best presented by measurements conducted under actinic light quality similar to that in which the plant was grown, since there could be important differences in plant response to measurement spectral quality and growth spectral quality (Chow et al., 1990). Therefore, Pn measurements with light quality similar to growth light quality may avoid confounding physiological and/or biochemical responses with alterations in whole-plant ultra structure and morphology.

The RGB treatment consisted of $61 \%$, $24 \%$, and $15 \%$ of red, green, and blue light, respectively. While RB treatment consists of $84 \%, 0 \%$, and $16 \%$ of red, green, and blue light, respectively, which is significantly red-biased. Although YPF and the amount of absorbed light were higher in the RB treatment, the RGB treatment resulted in greater biomass production. In this case, compensatory adjustments in the photosynthetic machinery to balance excitation energy between photosystems I and II (Chow et al., 1990; Murchie and Horton, 1998; Tennessen et al., 1994) could be induced by over-stimulated PSII, due to the narrowspectrum photosynthetic light energy from red LEDs in red-biased RB treatment. Perhaps, the RGB treatment achieved a balanced spectral environment by supplementing a favorable amount of green light to the plants.

On the other hand, since carbon gain capacity is a function of both total leaf area and Pn, increases in plant dry weight are not always associated with an increase in photosynthetic rate on a unit leaf area basis. Hence, stimulated leaf area production can completely counteract a reduction in Pn per unit leaf area, with the result that Pn by the plant is not reduced or is even increased (Bugbee and Salisbury, 1988). 


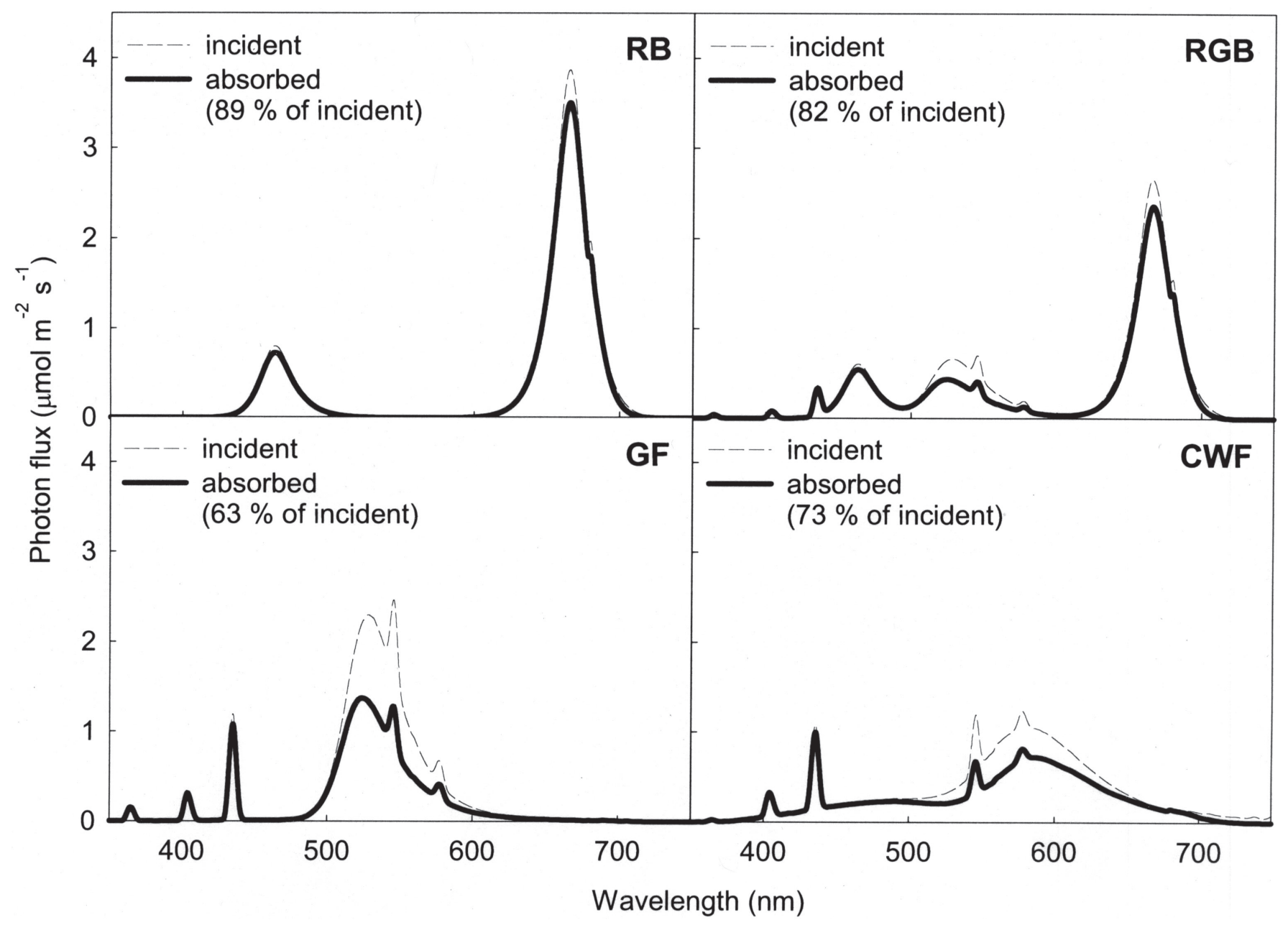

Fig. 3. Spectral distribution of absorbed light by lettuce leaves against incident light from red and blue LEDs (RB), red and blue LEDs with green fluorescent lamps (RGB), green fluorescent lamps (GF), and cool-white fluorescent lamps (CWF). The absorbed light was calculated from absorptance of lettuce leaves for each wavelength. The absorptance was calculated as absorptance $=1-$ (reflectance + transmittance). Reflectance and transmittance data were obtained with an integrating sphere attached to a spectroradiometer which measures the percentages of reflectance and transmittance.

A plant canopy with a high LAI can be as productive as a canopy having higher individual unit Pn, but with a overall lower LAI (Goins et al., 2001; Hunt, 1990). Although Pn among plants grown under RB, RGB, and CWF were similar, plants grown under RGB displayed a higher leaf area, which could facilitate greater light interception to improve photosynthesis at low light levels. Figure 2 demonstrates that a high LAI facilitated more incident radiation interception, which in turn enhanced the overall plant growth rate.

This investigation demonstrated that the addition of $24 \%$ green light ( 500 to $600 \mathrm{~nm}$ ) to red and blue LEDs (RGB treatment) enhanced lettuce growth compared to plants grown under cool-white fluorescent lamps (CWF treatment). Coincidentally, lettuce grown using RGB lighting would have an additional aesthetic appeal of a green appearance.

In this study, small fluorescent lamps that emit green light were installed with an array of red and blue LEDs. Considerable commercial interest has been directed toward improving green LEDs and, therefore, green LEDs that have high output and provide the required photon flux are more available now than before. Further studies are needed to determine required levels of green photons for optimum plant growth and more tests with different green peak wavelengths (using green LEDs) with red and blue LEDs would be useful in determining a green light response spectrum. These findings could then be used to design spectrally balanced LED systems for supporting plant growth, especially for very specialized applications, such as in space.

\section{Literature Cited}

Barta, D.J., T.W. Tibbits, R.J. Bula, and R.C. Morrow. 1992. Evaluation of light emitting diode characteristics for space-based plant irradiation source. Adv. Space Res. 12:141-149.

Brown, C.S., A.C. Schuerger, and J.C. Sager. 1995. Growth and photomorphogenesis of pepper plants under red light-emitting diodes with supplemental blue or far-red lighting. J. Amer. Soc. Hort. Sci. 120:808-813.

Bugbee, B. and F.B. Salisbury. 1988. Exploring the limits of crop productivity. I. Photosynthetic efficiency of wheat in high irradiance environments. Plant Physiol. 88:869-878.

Bula, R.J., R.C. Morrow, T.W. Tibbits, D.J. Barta, R.W. Ignatius, and T.S. Martin. 1991. Lightemitting diodes as a radiation source for plants. HortScience 26:203-205.

Chow, W.S., A. Melis, and J.M. Anderson. 1990. Adjustments of photosystem stoichiometry in chloroplasts improve the quantum efficiency of photosynthesis. Pro. Natl. Acad. Sci. 87:7502-7506.

Dougher, T.A. and B. Bugbee. 1999. Toward an understanding of blue light effects on diverse species: Implications for advanced life-support systems. SAE Tech. Paper 1999-01-2108.

Dougher, T.A.O. and B. Bugbee. 2001a. Differences in the response of wheat, soybean and lettuce to reduced blue radiation. Photochem. Photobio. 73:199-207.

Dougher, T.A.O. and B. Bugbee. 2001b. Evidence for yellow light suppression of lettuce growth. Photochem. Photobiol. 73:208-212.

Goins, G.D. 2002. Growth, stomatal conductance, and leaf surface temperature of Swiss chard grown under different artificial lighting technologies. SAE Tech. Paper 2002-01-2338.

Goins, G.D., J.C. Sager, R.M. Wheeler, L.M. Ruffe, and N.C. Yorio. 2001. Salad crop production under different wavelengths of red light-emitting diodes (LEDs). SAE Tech. Paper 200101-2422.

Goins, G.D. and N.C. Yorio. 2000. Spinach growth and development under innovative narrow- and broad-spectrum lighting sources. SAE Tech. Paper 2000-01-2290.

Goins, G.D., N.C. Yorio, M.M. Sanwo, and C.S. Brown. 1997. Photomorphogenesis, photosynthesis, and seed yield of wheat plants grown under red light-emitting diodes (LEDs) with and without supplemental blue lighting. J. Expt. Bot. 48:1407-1413. 
Goins, G.D., N.C. Yorio, and H. Vivenzio. 1998 Performance of salad-type plants using lighting and nutrient delivery concepts intended for spaceflight. J. Aerospace 107:284-289.

Hanba, Y.T.,H. Kogami, and I. Terashima. 2002. The effect of growth irradiance on leaf anatomy and photosynthesis in Acer species differing in light demand. Plant Cell Environ. 25:1021-1030.

Hoagland, D.R. and D.I. Arnon. 1950. The water culture method for growing plants without soil. Calif. Agr. Expt. Sta. Circ. 347.

Hoenecke, M.E., R.J. Bula, and T.W. Tibbitts. 1992. Importance of 'blue' photon levels for lettuce seedlings grown under red-light-emitting diodes. HortScience 27:427-430.

Huh, K.Y., J.H. Choi, K.S. Kim, and K.Y. Huh. 1997. Effects of light quality on growth and flowering of Hibiscus syriacus L. J. Kor. Soc. Hort. Sci. 38:272-277.

Hunt, R. 1990. Basic growth analysis. Unwin Hyman, Ltd., London.

Kim, H.H., R.D. Heins, and W.H. Carlson. 2002. Development and flowering of petunia grown in a far-red deficient light environment. Acta Hort. 580:127-135.

Klein, R.M. 1992. Effects of green light on biological systems. Biol. Rev. 67:199-284.

Klein, R.M., P.C. Edsall, and A.C. Gentile. 1965. Effects of near ultraviolet and green radiation on plant growth. Plant Physiol. 40:903-906.

Kliss, M. and R.D. MacElroy. 1990. Salad machine: A vegetable production unit for long duration space missions. SAE Tech. Paper 901280.

Lambers, H., F.S. Chapin, and T.L. Pons. 1998. Plant physiological ecology. Springer-Verlag, New York.

Langhans, R.W. and D.R. Dressen. 1988. Challenges to plant growing in space. HortScience 23:286-293.

Mackowiak, C.L., L.P. Owens, and C.R. Hinkle. 1989. Continuous hydroponic wheat production using a recirculating system. Natl. Aeronautics Space Admin. Tech. Memo. 102784.
McCree, K.J. 1972a. The action spectrum, absorptance and quantum yield of photosynthesis in crop plants. Agr. Meteorol. 9: 191-216.

McCree, K.J. 1972b. Test of current definitions of photosynthetically active radiation against leaf phootsynthesis data. Agr. Meteorol. 10:443-453.

Moran, R. 1982. Formulae for determination of chlorophyllous pigments extracted with $N, N$-dimethylformamide. Plant Physiol. 69:1376-1381.

Murchie, E.H. and P. Horton. 1998. Contrasting patterns of photosynthetic acclimation to the light environment are dependent on the differential expression of the response to altered irradiance and spectral quality. Plant Cell Physiol. 21:139-148.

Nobel, P.S. 1999. Physicochemical \& environmental plant physiology. Academic Press, San Diego.

Pearcy, R.W. 1998. Acclimation to sun and shade, p. 250-263. In: A.S. Raghavendra (ed.). Photosynthesis. A comprehensive treatise. Cambridge Univ. Press, Cambridge.

Preece, J.E. and P.E. Read. 1993. The biology of horticulture: an introductory textbook. John Wiley, New York.

Rajapakse, N.C., R.K. Pollock, and M.J. McMahon. 1992. Interpretation of light quality measurements and plant response in spectral filter research. HortScience 27:1208-1211.

Sager, J.C., W.O. Smith, J.L. Edwards, and K.L. Cyr. 1988. Photosynthetic efficiency and phytochrome photoequilibria determination using spectral data. Trans. Amer. Soc. Agr. Eng. 31:1882-1889.

Sager, J.C. and R.M. Wheeler. 1992. Application of sunlight and lamps for plant irradiance in space bases. Adv. Space Res. 12:133-140.

Salisbury, F.B. and B. Bugbee. 1988. Plant productivity in controlled environments. HortScience 23:293-299.

Salisbury, F.B. and M.A. Clark. 1996. Suggestions for crops grown in a controlled environment lifesupport systems, based on attractive vegetarian diets. Adv. Space Res. 18:33-39.

Salisbury, F.B. and C.W. Ross. 1992. Plant physiology. Wadsworth Publ. Co., Belmont.

Siefermann-Harms, D. 1985. Carotenoids in photosynthesis. I. Location in photosynthetic membranes and light-harvesting function. Biochimica et Biophysica Acta 811:325-355.

Siefermann-Harms, D. 1987. The light-harvesting and protective functions of carotenoids in photosynthetic membranes. Physiol. Plantarum 69:561-568.

Smith, H. 1993. Sensing the light environment: the functions of the phytochrome family, p. 377-416. In: R.E. Kendrick and G.H.M. Kronenberg (eds.). Photomorphogenesis in plants. Kluwer Academic Publ., Dordrecht.

Song, W.S., H.S. Park, and J.H. Lee. 1997. Effect of light quality on the growth of Hibiscus syriacus L. Res. Rpt. For. Gen. Res. Inst. Korea 33:104-111.

Sun, J., J.N. Nishio, and T.C. Vogelmann. 1998. Green light drives $\mathrm{CO}_{2}$ fixation deep within leaves. Plant Cell Physiol. 39:1020-1026.

Taiz, L. and E. Zeiger. 1991. Plant physiology. The Benjamin/Cummings Publ. Co., Inc., Redwood City, Calif.

Tennessen, D.J., E.L. Singsaas, and T.D. Sharkey. 1994. Light-emitting diodes as a light source for photosynthesis research. Photosynthesis Res. 39:85-92.

Yorio, N.C., G.D. Goins, H.R. Kagie, R.M. Wheeler, and J.C. Sager. 2001. Improving spinach, radish, and lettuce growth under red light-emitting diodes (LEDs) with blue light supplementation. HortScience 36:380-383.

Yorio, N.C., R.M. Wheeler, G.D. Goins, M.M Sanwo-Lewandowski, C.L. Mackowiak, C.S Brown, J.C. Sager, and G.W. Stutte. 1998. Blue light requirements for crop plants used in bioregenerative life support system. Life Support Biosphere Sci. 5:119-128. 